\title{
What can and should we predict in mental health?
}

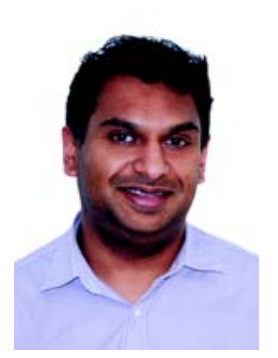

Astika Kappagoda Deputy Editor

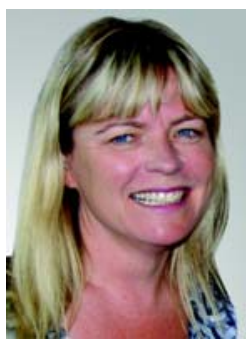

Ruth Armstrong Senior Deputy Edito

mja@mja.com.au

doi: 10.5694/mjal3.c0520

While prediction of suicide risk in individuals may be problematic, at a population level, suicide prevention has for some time been integral to mental health policies. Christensen and Petrie (page 472) outline six recommendations that should be part of any suicide prevention strategy. These revolve around targeting interventions, addressing risk factors, providing online resources and addressing gaps in community knowledge and discussion.

There have been recent moves to encourage more public discussion about suicide. But, as Fitzpatrick and Kerridge argue (page 470), community discussion should not simply be equated to media reporting of suicides. While there is some evidence of an association between increased media reporting and the incidence of attempted or completed suicide, they argue that this should not cloud strategies to encourage general community discussion about how suicide affects us all. There is reason to hope that talk beyond that filtered through the media prism will more effectively address the social and cultural factors that relate to suicide.

The possibility of identifying children at high risk of emotional and behavioural problems has been the basis of the expansion of the voluntary Healthy Kids Check for 3year-olds to include social and emotional wellbeing. Will such assessment predict later problems? Daubney and colleagues (page 475) argue that although early intervention in this age group does have benefits, many children with problems go undetected, and none of the currently available assessment instruments are suited to screening. In addition, no symptom clusters are predictive of later psychopathology, and there are potential problems with overdiagnosis and overmedicalisation.

From the outsider's perspective, there often seems to be more bad than good news in mental health, with controversy, lack of progress and confusing evidence. However, there are bright spots, even in those conditions previously thought to be intractable. Grenyer (page 464) shows that the prognosis for borderline personality disorder has significantly improved, with effective psychotherapies and support to patients and their family members offering real hope for more stable and productive lives. This should also lower sufferers' risk of suicide, which, either attempted or completed, is a well known feature of the disorder.

Twelve years after the publication of Infinite jest, David Foster Wallace committed suicide on a background of worsening, difficult-to-treat depression. His strangely prescient metaphor of flames rising up a burning building reaches beyond literary dilettantism. Perhaps, in the context of suicide, we need to ask ourselves whether we know what causes the fire, and how much we understand the person poised in terror at the top.

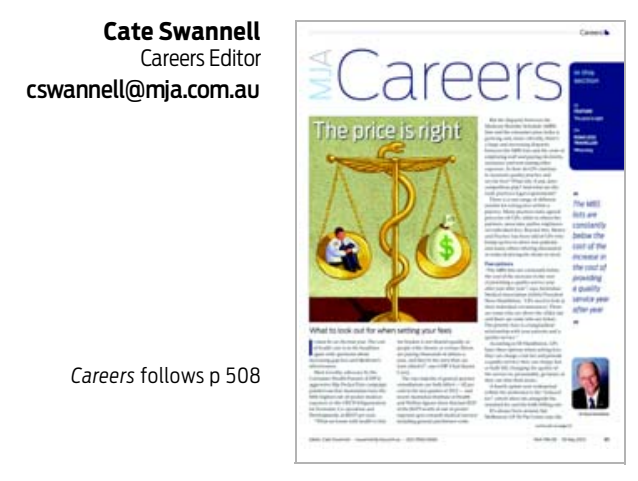

It is an election year and the cost of health care is constantly in the headlines. The Australian Competition and Consumer Commission recently issued an authorisation (A91334) enabling general practice partners and associates to work together to set prices within the practice and for practices to collectively bargain with Medicare Locals and public hospitals about the fees for medical services they provide, such as after-hours consultations. Annabel McGilvray spoke with
AMA President Dr Steve Hambleton and others about the dilemmas facing general practitioners and their practice managers (pages C1, C2) as they try to deliver quality care. Professor Jonathan Silberberg is an interventional cardiologist who produces online instructional videos for prospective doctors via his quirky creation, Prof Montage. Cate Swannell talked to him about why humour is important in the learning process (page C4). 